\title{
Evaluation of the WRF Double-Moment 6-Class Microphysics Scheme for Precipitating Convection
}

\author{
Song-You Hong, ${ }^{1}$ Kyo-Sun Sunny Lim, ${ }^{1}$ Yong-Hee Lee, ${ }^{2}$ Jong-Chul Ha, ${ }^{2}$ Hyung-Woo Kim, ${ }^{3}$ \\ Sook-Jeong Ham, ${ }^{3}$ and Jimy Dudhia ${ }^{4}$ \\ ${ }^{1}$ Department of Atmospheric Sciences and Global Environment Laboratory, Yonsei University, Seoul 120-749, Republic of Korea \\ ${ }^{2}$ Forecast Research Laboratory, National Institute of Meteorological Research, Korea Meteorological Administration, \\ Seoul 156-010, Republic of Korea \\ ${ }^{3}$ 73rd Weather Group, Korea Air Force, Chungnam 321-923, Republic of Korea \\ ${ }^{4}$ Mesoscale and Microscale Meteorology Division, National Center for Atmospheric Research, Boulder, CO 80305, USA
}

Correspondence should be addressed to Song-You Hong, shong@yonsei.ac.kr

Received 24 December 2009; Revised 23 February 2010; Accepted 8 April 2010

Academic Editor: Zhaoxia Pu

Copyright (C) 2010 Song-You Hong et al. This is an open access article distributed under the Creative Commons Attribution License, which permits unrestricted use, distribution, and reproduction in any medium, provided the original work is properly cited.

\begin{abstract}
This study demonstrates the characteristics of the Weather Research and Forecasting (WRF) Double-Moment 6-Class (WDM6) Microphysics scheme for representing precipitating moist convection in 3D platforms, relative to the WSM6 scheme that has been widely used in the WRF community. For a case study of convective system over the Great Plains, the WDM6 scheme improves the evolutionary features such as the bow-type echo in the leading edge of the squall line. We also found that the WRF with WDM6 scheme removes spurious oceanic rainfall that is a systematic defect resulting from the use of the WSM6 scheme alone. The simulated summer monsoon rainfall in East Asia is improved by weakening (strengthening) light (heavy) precipitation activity. These changes can be explained by the fact that the WDM6 scheme has a wider range in cloud and rain number concentrations than does the WSM6 scheme.
\end{abstract}

\section{Introduction}

The Weather Research and Forecasting (WRF) model [1] is a community numerical weather prediction (NWP) model that is applicable to various scales of weather phenomena. Application of the WRF model has recently been extended to resolving regional details embedded within climate signals from the general circulation model [2]. As computer resources become available, the use of high-resolution WRF with a horizontal grid spacing of less than $5 \mathrm{~km}$ will improve forecasts for convective-scale phenomena, including explicit information about the timing, intensity, and mode of convection (e.g., $[3,4]$ ). These previous reports demonstrate a $4-\mathrm{km}$ resolution in WRF forecasts, which explicitly resolves convection yields for better guidance in precipitation forecasts, in comparison to $12-\mathrm{km}$ resolution. Microphysical schemes are explicit, whereas convective parameterizations are implicit. As grid spacings decrease, convective parameterizations become more inappropriate (and scientifically questionable given the underlying assumptions), whereas the explicit representation of microphysical processes can be computed for increasingly small clouds, cloud particles, water droplets, and so forth.

In the WRF model, there are multiple choices for each physical component; for example, there are ten algorithms for the cloud microphysics scheme, as of August 2009. Among the microphysics packages for clouds and precipitation, the series of the WRF single-moment (WSM) schemes (WSM3, WSM5, and WSM6 [5, 6]) has been widely used. As of June 2009, there are about 50 institutions across the globe running the WRF model on a real-time basis, and many of these institutions chose the WSM scheme for the microphysics option. As an example, the WRF model with the WSM6 microphysics has provided useful information on high-resolution weather phenomena over the Great Plains in the US [7, 8]. The Korean Meteorological Administration (KMA) and Korean Air Force (KAF) have also chosen the WSM6 scheme for real-time forecasts over East Asia, as noted 
by Ha et al. [9] and Byun et al. [10]. There are numerous reports evaluating the performance of the WRF with WSM microphysics on various weather phenomena, including over the US [11], for a hurricane over the Atlantic [12], heavy rainfall over East Asia [13] and polar weather [14]. Huang et al. [15] used the WSM5 scheme to develop an advanced data assimilation system. Otkin and Greenwald [16] evaluated the WSM6 scheme using the MODIS-derived cloud data.

These studies demonstrated that the WSM schemes are competitive options in WRF by reproducing precipitating convection and associated meteorological phenomena. However, some systematic deficiencies have been reported, such as too much light precipitation activity [17] and an excessive amount of graupel, as compared to snow [18]. Spurious light precipitation was a systematic problem in the KMA forecast systems, as noted by Jo et al. [19]. A further revision to the WSM6 scheme employing a combined sedimentation velocity for graupel and snow [20] helped to alleviate the problem of excessive graupel, but weak radar reflectivity remained a systematic problem (personal communication with J. Kain).

The WRF Double-Moment 6-class (WDM6) scheme [21] was announced to the WRF community in April 2009. The WDM6 scheme enables the investigation of the aerosol effects on cloud properties and precipitation processes with the prognostic variables of cloud condensation nuclei $(\mathrm{CCN})$, cloud water and rain number concentrations. The WDM6 scheme has been evaluated on an idealized two-dimensional thunderstorm testbed [21], but its overall characteristics relative to the WSM6 scheme for 3D real cases has not been provided. For these reasons, it is crucial to provide physical reasons for the differences in simulated precipitation and clouds between the WDM6 and WSM6 schemes.

A squall-line case over the Great Plains in the US will be simulated with both WSM6 and WDM6 microphysics schemes. In Lim and Hong [21], the fundaments in the WDM6 were described in detail, but the differences in the simulated convection were demonstrated only for an idealized 2D storm. The purpose of a specific squall-line simulation is to evaluate the basic differences in convective activities between the WSM6 and WDM6 schemes in a real 3D model framework, prior to a robust evaluation of the hydrometeors and investigation studies on associated dynamics. Experimental evaluations of the WDM6 scheme over the WSM6 scheme at a real-time forecast platform at KMA have not shown distinct discrepancy in the predicted precipitation, but at times there have been cases that the WDM6 scheme is superior to the WSM6 scheme. A reduction of spurious precipitation in the case of the WSM6 scheme was systematically alleviated by the WDM6 scheme. We will demonstrate a mid-latitude cyclogenesis in East Asia as an example. As another evaluation tool, a regional climate modeling approach is adapted to examine the characteristics of a summer monsoon precipitation in East Asia. We focus on differences in the simulated precipitation with a possible physical reasoning on the fundamental differences in microphysics between the WSM6 and WDM6 schemes. The causes for the different model performances in the underlying assumptions of WSM6 and WDM6 schemes will be investigated. In addition, a statistical measure of skill in precipitation forecasts over South Korea in summer 2008 will be shown in the final section.

\section{Model Setup}

2.1. Overview of the WDM6 Scheme. Prognostic water substance variables include water vapor, clouds, rain, ice, snow, and graupel for both the WDM6 [21] and WSM6 [5] schemes. Additionally, the prognostic number concentrations of cloud and rain waters, together with the $\mathrm{CCN}$, are considered in the WDM6 scheme. The number concentrations of ice species such as graupel, snow, and ice are diagnosed following the ice-phase microphysics of Hong et al. [6]. This simplicity is theoretically based on the fact that the prediction of ice-phase number concentrations has significantly less impact on the results than the prediction of warm-phase concentrations in deep convective cases [22]. The activated CCN number concentration is predicted and formulated using the drop activation process based on Twomey's relationship between the number of activated CCN and supersaturation [23, 24], which enables a level of complexity to be added to the traditional bulk microphysics schemes through the explicit CCN-cloud drop concentration feedback. The complete evaporation of cloud drops is assumed to return corresponding $\mathrm{CCN}$ particles to the total CCN count. The CCN number concentration can be regulated under the forced large-scale environment, even for the seasonal climate cases. Any other CCN sink/source terms, except for CCN activation and droplet evaporation, are ignored in the WDM6 scheme. Further details on the CCN activation process are described in appendix A of Lim and Hong [21]. Accurate 3D CCN information is an important aspect of model simulations. However, obtaining real-time CCN information in both the horizontal and vertical directions is difficult. Thus, we chose an initial value of $100 \mathrm{~cm}^{-3}$ for the CCN number concentration in this study, as in Lim and Hong [21].

The formulation of warm-rain processes such as autoconversion and accretion in the WDM6 scheme is based on the studies of Cohard and Pinty [25]. For other source and sink terms in warm-rain processes, the formulas in the WSM6 scheme were adopted. However, the microphysics processes in the WDM6 scheme, even if the same formula is applied, work differently from those in the WSM6 scheme due to the predicted number concentrations of cloud water and rain, which in turn indirectly influence the ice processes. Lim and Hong [21] demonstrated that, compared to the simulation of an idealized $2 \mathrm{D}$ thunderstorm with the WSM6 scheme, the higher drop concentrations in the convective core versus lower drop concentrations in the stratiform region are distinct in the WDM6. A marked radar bright band near the freezing level was produced with the WDM6 microphysics scheme. Meanwhile, the WSM6 scheme extended strong reflectivity to the ground level over the stratiform region. The aerosol effects on the cloud/rain properties and surface precipitation were also investigated by 
varying the initial CCN number concentration. Varying the CCN number concentration had a nonmonotonic impact on rainfall amount.

2.2. Experimental Setup. The model used in this study is the Advanced Research WRF version 3.1 [1]. The physics packages, other than the microphysics, included the KainFritsch cumulus parameterization scheme [26], the unified Noah land-surface model [27], a simple cloud-interactive shortwave radiation scheme [28], the Rapid Radiative Transfer Model (RRTM) longwave radiation scheme [29], and the Yonsei University planetary boundary layer (PBL) scheme, for vertical diffusion [30]. The PBL scheme was replaced with the Mellor-Yamada-Janjic (MYJ) scheme [31,32] for the squall line case over US. The MYJ scheme has been widely evaluated for convective systems over the Great Plains in the US (e.g., $[3,4])$.

The model configuration consisted of a nested domain defined on a Lambert conformal projection for all the selected cases. For a squall-line case over the US Great Plains, we followed the same model configuration of Shi et al. [17]. They investigated the impact of microphysical schemes on the IHOP_2002 case. From the comparison between the results from this study and those from Shi et al. [17], we can easily examine the advantage of the WDM6 scheme. A $1-\mathrm{km}$ model covering Oklahoma (Domain 3, $540 \times 465$ ) was surrounded by a $3-\mathrm{km}$ grid model (Domain 2, 480 $\times 351$ ), which in turn was nested by a $9-\mathrm{km}$ grid model (Domain 1, $300 \times 201)$ using a two-way interaction. Model integration was conducted during a 36-hour period, from 0000 UTC June 12 to 1200 UTC June 13, 2002. The cumulus parameterization was applied, except for the 1-km and 3$\mathrm{km}$ grid models for this case. A 30-km model covered the East Asia region $(199 \times 189)$ for a mid-latitude cyclogenesis case. This model configuration is identical to the model setup for operational forecasts at KMA, as of summer 2008. The experiments were performed for 36 hours, from 0000 UTC February 23 to 1200 UTC February 24, 2008. For a summer monsoon case in East Asia, a 50-km WRF was nested using analyzed data from the month of July 2006. The domain covers the East Asian monsoon regions $(109 \times 86)$ centered over the Korean peninsula. This configuration is identical to the model setup for several regional climate studies over East Asia (e.g., [33]). Koo and Hong [33] demonstrated that the WRF model is capable of reproducing the climatology and precipitation embedded within the summer monsoon over East Asia with the same model configuration of this study. The whole grid systems had 27 vertical layers, and the model top was located at $10 \mathrm{hPa}$ for all the simulated cases. Initial and boundary conditions were generated by the National Centers for Environmental Prediction (NCEP)-Final Analysis (FNL) data on $1^{\circ} \times 1^{\circ}$ global grids, every six hours.

The Tropical Rainfall Measuring Mission (TRMM) TRMM Multisatellite Precipitation Analysis (TMPA; [34]) data on a $0.25^{\circ} \times 0.25^{\circ}$ were used for an evaluation of the simulated precipitation. In addition, simulated reflectivities were verified against observed ones, which were obtained from the WSI IHOP Sector Mosaic Reflectivity Imagery (2-km) provided by the NCAR/EOL across the United States $[35,36]$ for the squall-line case.

\section{Results and Discussion}

3.1. Squall Line Case over the US Great Plains. Thompson et al. [37] and Weisman et al. [38] recognized that the WSM6 scheme tends to produce isolated intense convective cores compared to other schemes, such as that of Thompson [39]. This defect in the WSM6 scheme often failed to produce radar reflectivity and the associated mesoscale features of squall lines. The International $\mathrm{H}_{2} \mathrm{O}$ project (IHOP_2002) was conducted over southern Kansas, Oklahoma, and northern Texas for six weeks during May and June of 2002 (13 May to 25 June 2002). A detailed summary of the physical processes (i.e., mesoscale convergence lines and gust fronts) associated with convective storm initiation and evolution for IHOP cases can be found in Wilson and Roberts [40].

Figure 1 compares the radar reflectivity and numbered gust fronts associated with a squall line that developed on 12 June in Kansas and moved southeastward. The WRF was initialized at 00 UTC 12 June 2002, and the simulation results at the $24-\mathrm{hr}, 27-\mathrm{hr}$, and $30-\mathrm{hr}$ forecast times are shown. Here, we focus on the evolutionary feature of the squall line passed Oklahoma between 0000 UTC 13 June and 0600 UTC 13 June, which can be evaluated though the comparisons with the available observations.

The observed data at 00 UTC 13 (Figure 1(a)) exhibits a line type convection core stretching from the Texas panhandle northeastward to the border between Kansas and Oklahoma. Wilson and Roberts [40] demonstrated that gust fronts 3 and 4 initiate many more storms than gust fronts 1 or 2 . With time gust fronts 3 and 4 merge and a continuous squall line results in Figure 1(d). The storms associated with gust front 2 soon die, as does the gust front. The storms associated with gust front 1 live longer but never organize into a significant squall line. They also discovered that the most important factor for storm initiation and longevity is the gust front differential wind velocity. Generally, upward motion beginning in the boundary layer near the gust front extends up through the convective region, and slops more gently into the base of the trailing stratiform cloud. This descending current passes through the melting level, and finally enters the back of the convective region at low levels where it reinforces convergence at the leading gust front. Thus, the near-surface wind, normal to gust fronts, can enhance the convergence and organize a strong squall line.

The WSM6 run shows ambiguous separation of the two storms associated with gust fronts 3 and 4, showing larger convective areas than the observed areas data at 00 UTC 13 (Figure 1(b)). These storms do not develop into a continuous squall line after 3 hours. The storms associated with gust fronts 3 and 4 are well organized in the WDM6 run. After 3 hours, these storms are combined and the squall line traveled southeastward in central Oklahoma. However, the strength of reflectivity from the WDM6 run is systematically higher in a broad region compared to the WSM6 run and observations. In addition, the WDM6 run shows narrowed 


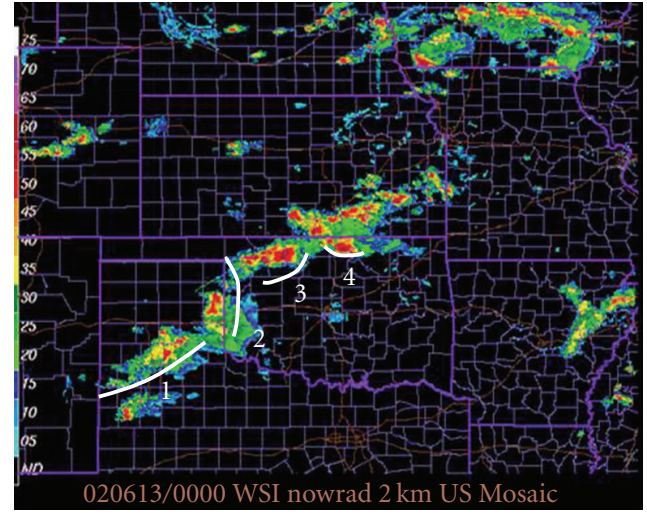

(a)

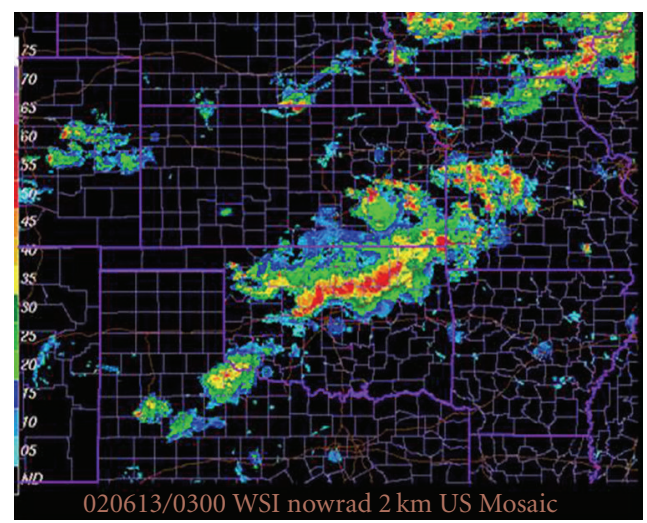

(d)

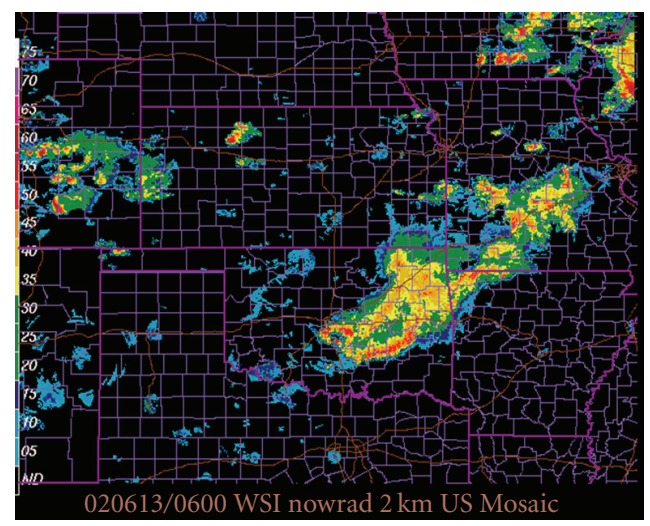

(g)

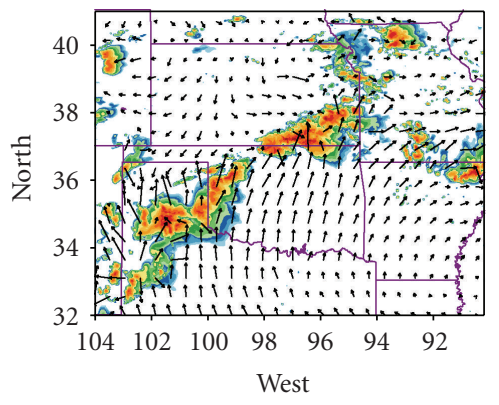

$\longrightarrow 20$

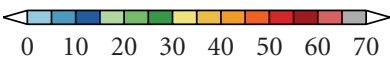

(b)

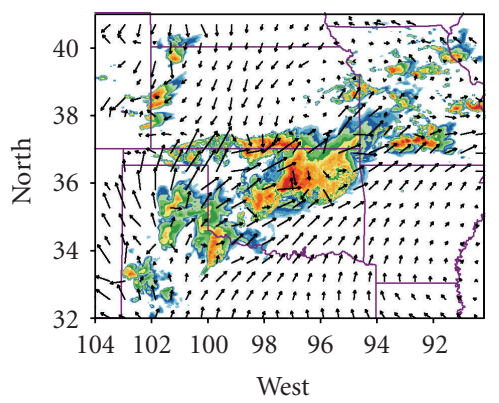

$\longrightarrow 20$

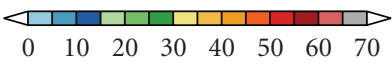

(e)
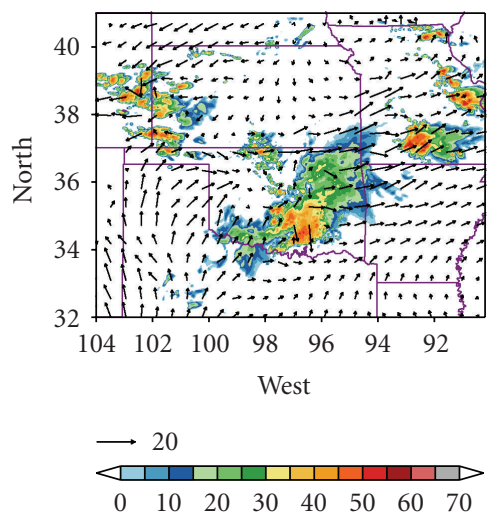

(h)

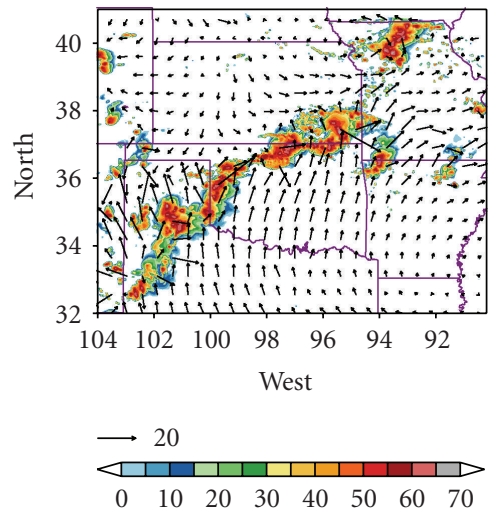

(c)

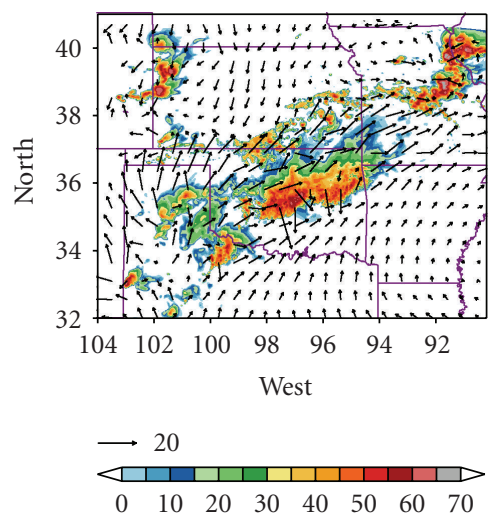

(f)

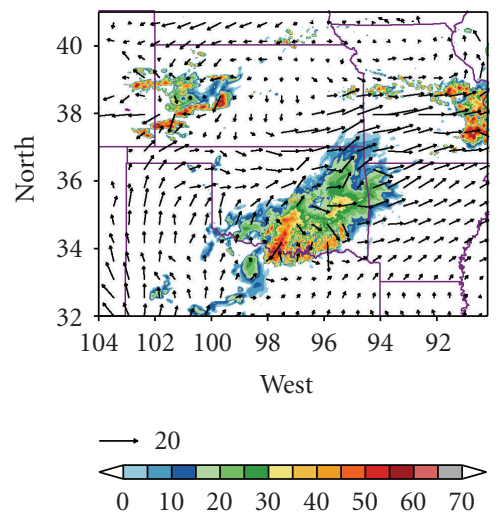

(i)

FIgure 1: Radar reflectivity (in dBZ) and numbered gust fronts for a squall line case over the US. (a) The observed WSI IHOP Sector Mosaic reflectivity (2-km) at 00UTC 13 June 2002 (URL: http://data.eol.ucar.edu/codiac/dss/id=77.091). Note that these images are a vertical composite of reflectivity and depict the highest reflectivity measured over each point on the Earth's surface. (b) and (c) are from the WSM6 and WDM6 experiments, respectively. The reflectivities were calculated from model-simulated precipitation particles (rain, snow, and graupel). The plotted results are from the second domain (i.e., 3-km resolution). Three figures in the second row are the same as (a), (b), and (c), except they were observed at 03UTC 13 June 2002. Figures in the third row represent same fields at 06UTC 13 June 2002. Here, the vectors denote the $850-\mathrm{hPa}$ wind $\left(\mathrm{ms}^{-1}\right)$.

areas of convection and the line-type band (Figure 1(c)). A reduction in light precipitation is noted in the Oklahoma panhandle at 0300 UTC in the WDM6 compared to the WSM6, as well as northeast Kansas and western Missouri at 0000 UTC. Convection in Missouri looks overdone at 0300
UTC in the WDM6 run. However, not much improvement is seen in Texas with the WDM6 microphysics scheme. During the weakening and dissipating stages (Figures $1(\mathrm{~g}), 1(\mathrm{~h})$, and 1(i)), both experiments fail to simulate strong convection in the leading edge of a squall line, but with a better 

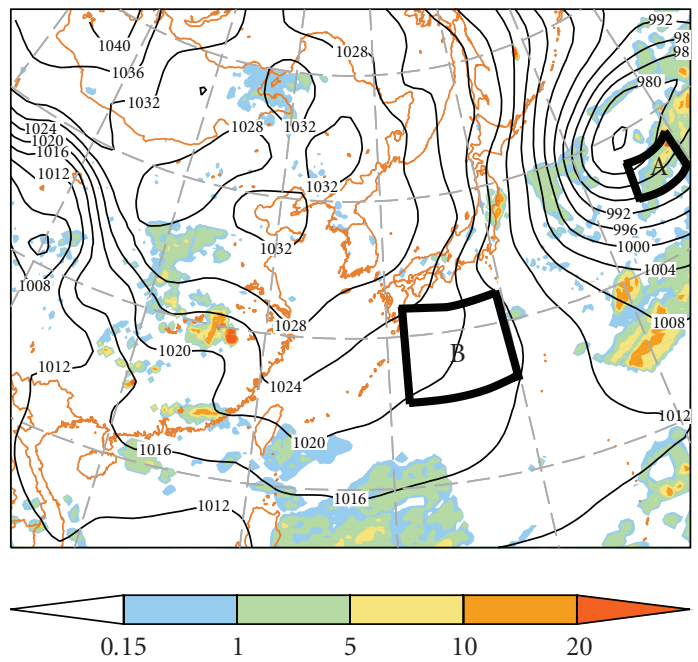

(a)
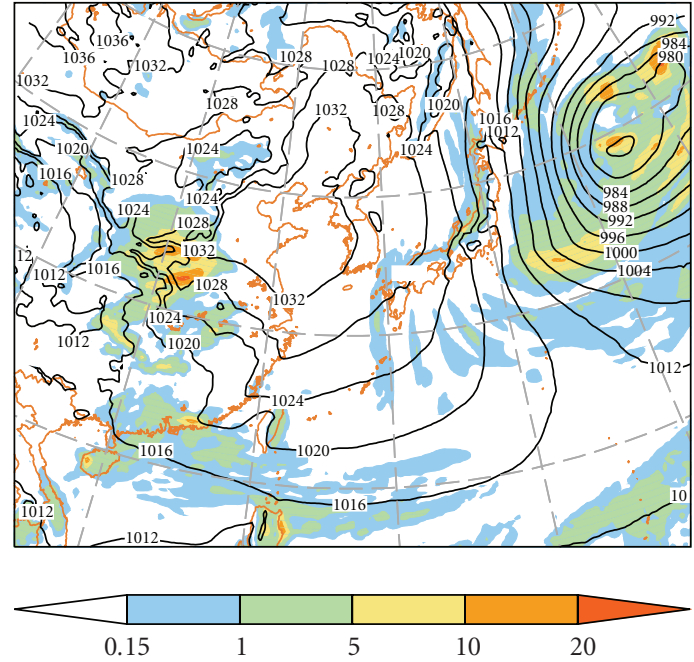

(b)
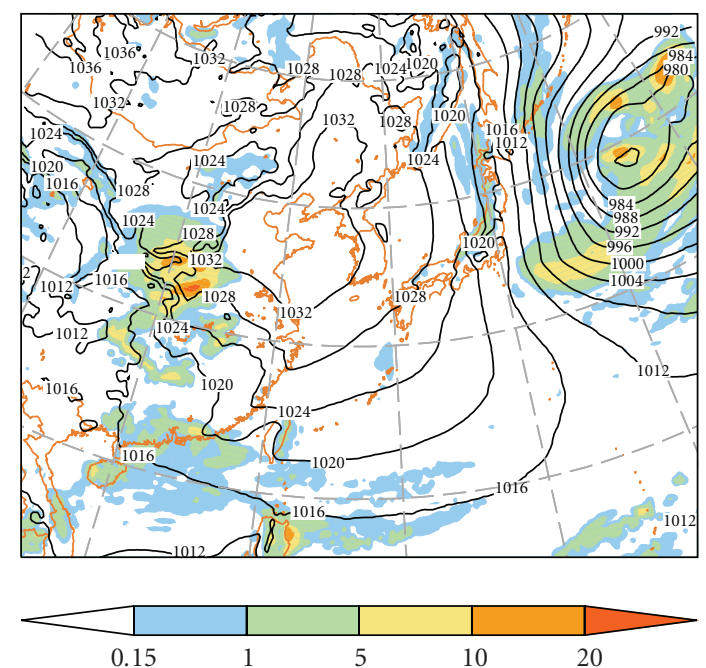

(c)

FIgURE 2: The 6 hours accumulated rainfall amount (mm) and averaged sea level pressure (SLP) from 0600 UTC to 1200 UTC 24 February 2008, obtained from the (a) TMPA observation for the rainfall and FNL data for the SLP, (b) WSM6, and (c) WDM6 experiments. Model integrations were conducted during the 36-h from 0000 UTC 23 February 2008. The marks "A" and "B" in Figure 2(a) designate the precipitating and nonprecipitating areas.

organized lined-up convection by the WDM6 experiment. This precipitating storm soon dissipates in both simulations at 1100 UTC, which is agreement with the observation (not shown).

The relatively narrower area of stratiform rain in the WDM6 run results from a larger number of rain number concentrations having smaller size, which causes rain to fall slowly on the ground, compared with the WSM6 run. Lim and Hong [21] noted that the WDM6 run shows well organized downdrafts with a strengthened cold pool, leading a slightly faster movement of the convective system, as compared to the WSM6 run within an idealized 2D thunderstorm testbed. Therefore, a possible reason for the faster movement of the squall line in the WDM6 run than in the WSM6 run in Figure 1 can be deduced from a strengthened cold pool. Further study on the impact of microphysics on the evolutionary features of the convective storms and associated cloud dynamics is needed. In addition, it is no doubt that the more realistic squall-line evolution might not be achieved with other cases under different thermodynamic condition.

3.2. Oceanic Cyclogenesis. At KMA, the WRF model was run with $10-\mathrm{km}$ resolution centered over South Korea, which is nested by a $30-\mathrm{km}$ coarse mesh model from May 2007. The WRF model outperformed the operational regional model, which is based on the PSU/NCAR MM5 [41], in terms of statistical skill score for forecasted rainfall. However, it was often observed that the WRF with the WSM6 scheme produced spurious precipitation over the 


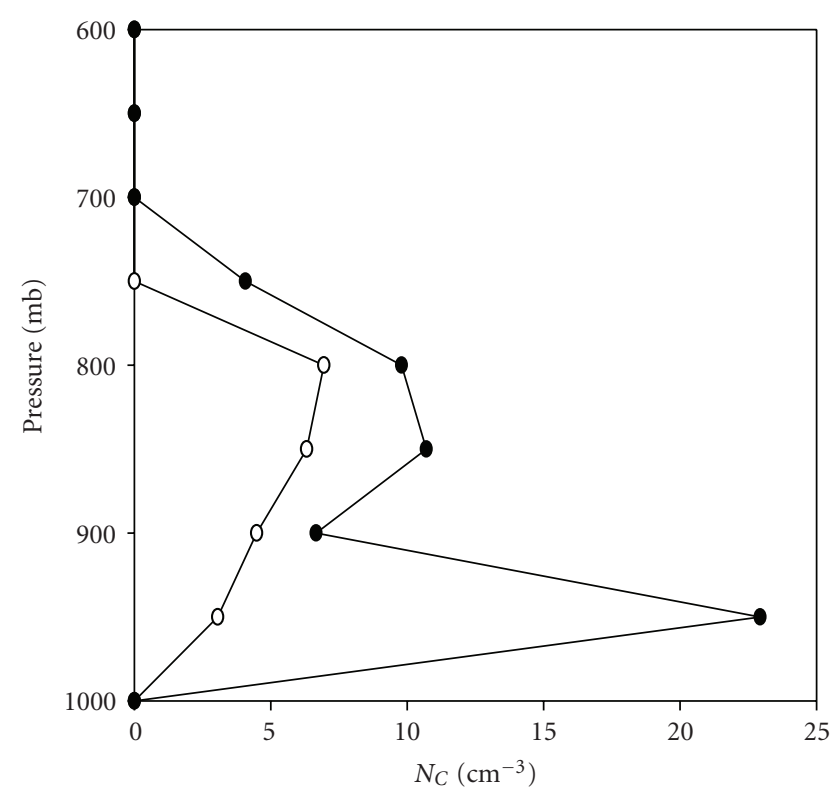

(a)

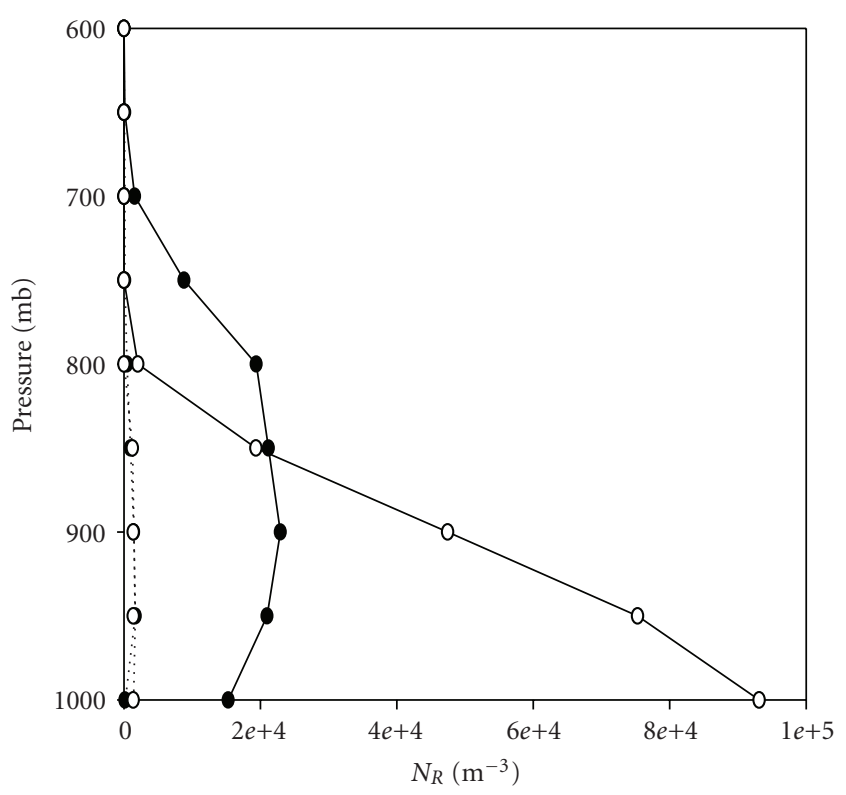

(b)

FIGURE 3: Modeled number concentrations of (a) cloud droplets and (b) raindrops over the regions "A" (closed circles) and "B" (open circles), as marked in Figure 2(a). The region "A" represents a relatively heavy rainfall region near the center of a cyclone, whereas a nonprecipitating cloud region is observed in region " $\mathrm{B}$." The values are obtained from the cloud area averaged values during the six hours from 0600 UTC to 1200 UTC 24 February 2008. Solid lines indicate the results from the WDM6 scheme and dotted lines are from the WSM6 scheme. The number concentration for raindrops can be calculated using the slope of rain size distribution and intercept parameter of rain in the WSM6 microphysics scheme. A cloudy area is defined as either $q_{C}>0.01 \mathrm{~g} \mathrm{~kg}^{-1}$ or $q_{R}>0.01 \mathrm{~g} \mathrm{~kg}^{-1}$.

oceans (e.g., Figure 2). The modeled precipitation with the WSM6 scheme exhibits banded precipitation activity over the southern part of Japan, which is absent in the TMPA observation (cf. Figures 2(a) and 2(b)). Precipitation over the subtropics near the southern boundary of the model domain and near the center of the cyclone is excessive. Such an excessively light precipitation is greatly reduced when the WDM6 scheme is employed. The KAF real-time forecasts verified that occasional spurious light precipitation over South Korea in the case of a WSM6 run was also removed by employing the WDM6 scheme, as shown by Byun et al. [10].

Figure 3 shows the modeled cloud droplets and raindrop concentrations averaged over the regions " $\mathrm{A}$ " $\left(34^{\circ}-37.5^{\circ} \mathrm{N}\right.$, $\left.154.5^{\circ}-160^{\circ} \mathrm{E}\right)$ and "B" $\left(26^{\circ}-32^{\circ} \mathrm{N}, 132^{\circ}-140^{\circ} \mathrm{E}\right)$, as marked in Figure 2(a). The region "A" represents a relatively heavy rainfall region near the center of a cyclone, whereas a non-precipitating cloud region is observed in region "B." The number concentrations of cloud droplets from the WDM6 scheme vary according to the convective activity and reveal larger values over region "A" than over region "B". A direct comparison of cloud droplet number concentrations between the WDM6 and WSM6 schemes is less meaningful since the CCN interacts explicitly with cloud droplets, and the cloud droplet number concentrations, which is predicted from the governing equation including the $3 \mathrm{D}$ advection and the source/sink of the number concentration in the WDM6 scheme, can be modulated according to the environmental features. Nevertheless, the comparison of cloud number concentration in Figure 3 shows that the constant value of $300 \mathrm{~cm}^{-3}$ for the cloud water number concentration in the WSM6 scheme is not an appropriate representation of various types of clouds.

In terms of the number concentration of raindrops, the WSM6 scheme produces a rather uniform distribution in the vertical direction, and the differences in number concentration of raindrops between the regions " $\mathrm{A}$ " and "B" are not significant, with a constant intercept parameter value of $8 \times 10^{6} \mathrm{~m}^{-4}$ for rain. Meanwhile, the WDM6 scheme shows a large variation in rain number concentration in both the horizontal and vertical directions with a flexible size distribution of rain, which is modulated with different microphysical processes according to the precipitation type and the characteristics of convection. A relatively larger number of rain drops over the region " $\mathrm{B}$ " implies the existence of nonsedimenting small raindrops. As a result, the WDM6 scheme effectively suppresses the spurious light precipitation through the enhanced evaporation of small droplets. A more realistic distribution of particle sizes for clouds and raindrops and associated microphysics would provide a physical feedback to the convective environment.

3.3. Monsoonal Rainfall in July 2006. The regional climate simulation by analyzed large-scale forcing is an efficient way to evaluate model performance [42]. The WRF model with the WSM6 scheme is capable of reproducing two major rain bands, one over the subtropics covering South China and the 


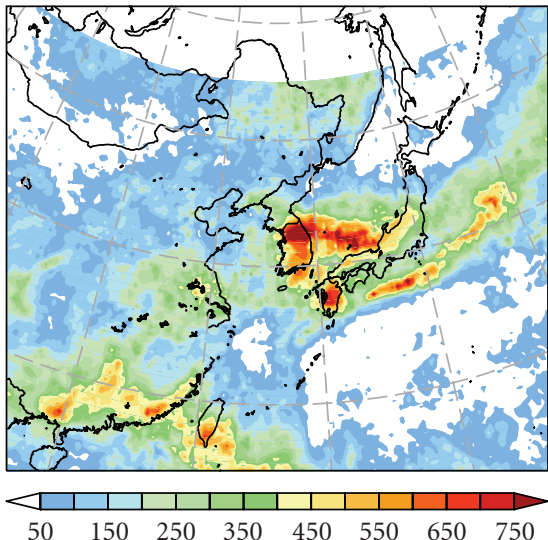

(a)

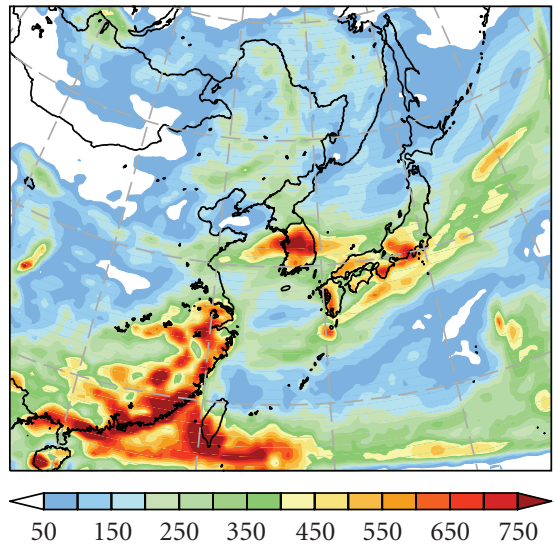

(b)

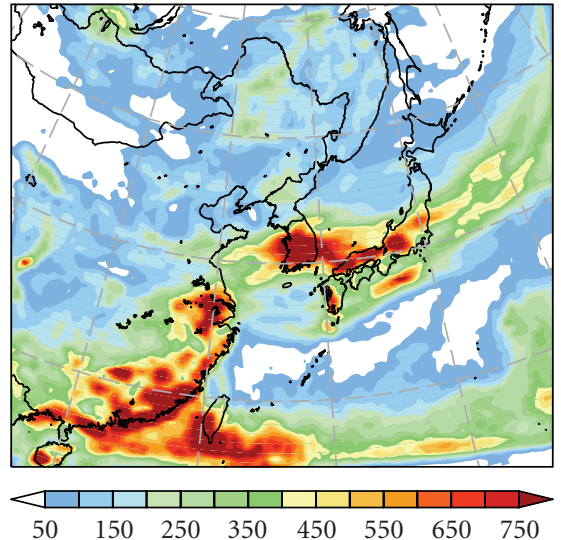

(c)

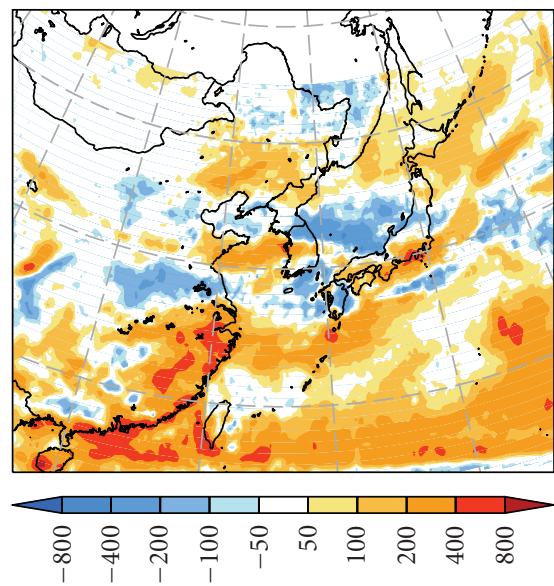

(d)

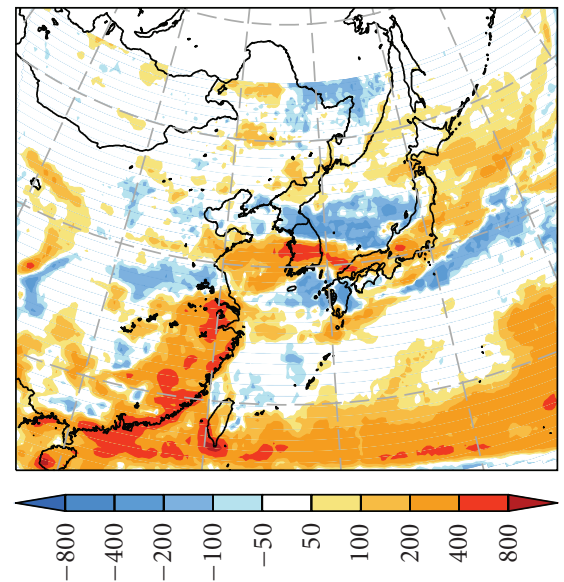

(e)

FIgURE 4: One-month accumulated rainfall (mm) from 0000 UTC 1 July to 0000 UTC 1 August 2006, obtained from the (a) TMPA observation, (b) WSM6, and (c) WDM6 experiments. Differences in 7 one-month accumulated rainfall (mm) between the observation and the (d) WSM6 (WSM6-TMPA) 8 and (e) WDM6 experiment (WDM6-TMPA).

TABLE 1: The pattern correlation coefficients (PC), bias score, and root mean square error (RMSE) of the 24 hours accumulated precipitation over South Korea with respect to surface observation, ending at 00 UTC 15 July 2001, for 5-km(45 km) resolution.

\begin{tabular}{lccccr}
\hline & \multicolumn{3}{c}{ Over the lands } & \multicolumn{2}{c}{ Over the oceans } \\
& PC & Bias score & RMSE & PC & Bias score \\
\hline WSM6 & 0.71 & 20.41 & 128.97 & 0.53 & 70.36 \\
WDM6 & 0.74 & 20.61 & 135.69 & 0.60 & 56.59 \\
\hline
\end{tabular}

southeastern China Sea and the other in the mid-latitudes, where local maxima appears over Korea and Japan. These major summer rainfall features are simulated, irrespective of the microphysics scheme (Figure 4). One obvious deficiency in the WSM6 run is excessive rainfall over the northwestern Pacific Ocean, south of Japan. A large portion of the ocean is covered by the one-month accumulated rainfall of over $100 \mathrm{~mm}$, which is largely alleviated in the WDM run. Table 1 shows the statistical skill score for precipitation over the lands and oceans. Even though the WDM6 shows slightly larger score in bias and root mean square error over lands, which is mainly due to heavy precipitation over Korea, significant improvement is shown over the oceans.
A close inspection reveals that a surplus rainfall in Manchuria and a deficit in the upper Yangtse river basin appear in the WSM run, which are improved in the WDM run. It is hard to interpret the physical reasoning for the different simulations within a $3 \mathrm{D}$ regional climate platform, thus, we compare the PDF of the simulated precipitation with those of the WSM6 and WDM6 schemes (Figure 5). It is clear that compared to the single-moment approach, the double-moment scheme suppresses the rainfall activity in the light precipitation categories, whereas it enhances the activities in the moderate and heavy categories. The above comparison of the two schemes qualitatively complies with the characteristics of the WDM microphysics over the WSM 


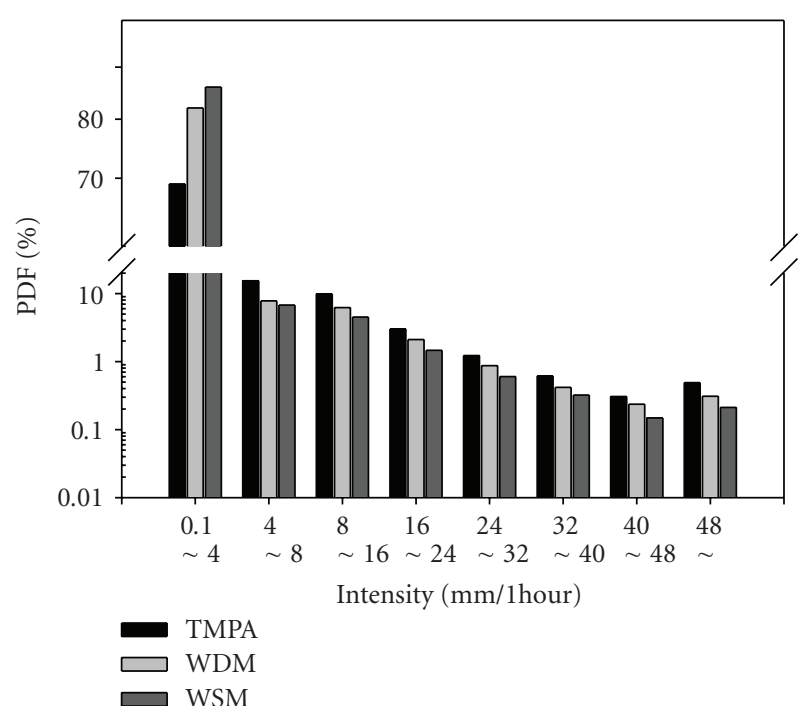

FIgUre 5: Probability Distribution Function (PDF) of three-hour accumulated rainfall intensity from the TMPA observations, and the corresponding results from the WDM6 and WSM6 experiments over the whole domain during the one month from 0000 UTC 1 July to 0000 UTC 1 August 2006.

algorithm in the 2D squall line case study of Lim and Hong [21], in that the WDM6 was responsible for the light (heavy) precipitation suppression (enhancement).

\section{Concluding Remarks}

The WRF model sensitivity to microphysical parameterization was analyzed from the WSM6 to the WDM6 scheme for the selected 3D test platforms. The case study for a squall line over the US Great Plains showed that the traveling speed of the simulated squall line is faster with the higher radar reflectivity when the double-moment scheme is used. It also appears that the double-moment approach of the WDM6 scheme tends to resolve known systematic deficiencies in the corresponding single-moment approach of the WSM6 scheme. The WDM6 run suppressed spurious light precipitation over the oceans. The simulated monsoonal summer rainfall climate over East Asia was improved by suppressing the light precipitation and enhancing the heavy precipitation.

A statistical evaluation of the precipitation forecast skill over South Korea in summer 2008 was made (Figure 6). The Korea Local Analysis and Prediction System (KLAPS) was developed for the operational very short range forecast with $5 \mathrm{~km}$ horizontal resolution [9]. A diabatic initialization technique was applied to the KLAPS with the use of radar reflectivity and satellite data. The scores confirmed that the forecasted precipitation using the WDM6 scheme was better than that with the WSM6 scheme for both the light and heavy precipitation categories in terms of the equitable threat score (ETS; [43]). In contrast to the previous evaluation cases, the amount of light precipitation is also increased during the first 6 hours forecast period. This may be a negative impact of

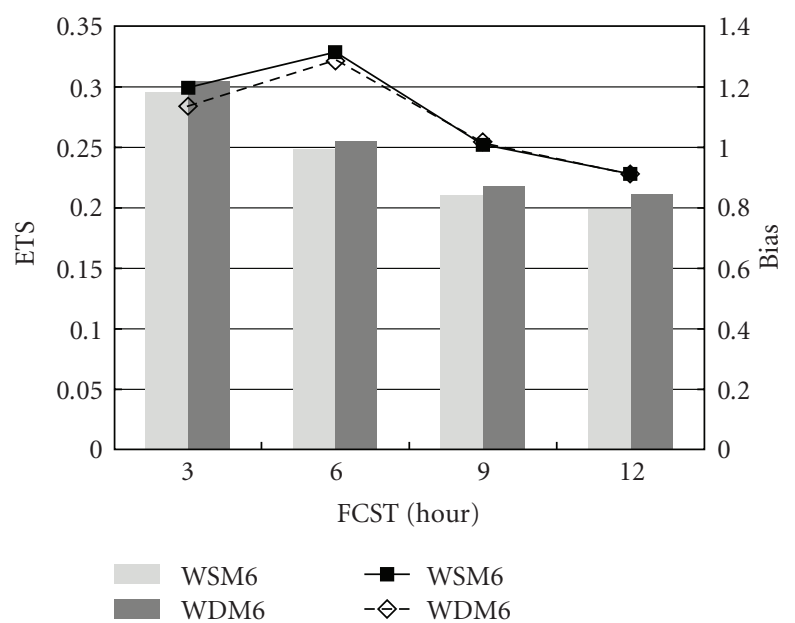

(a)

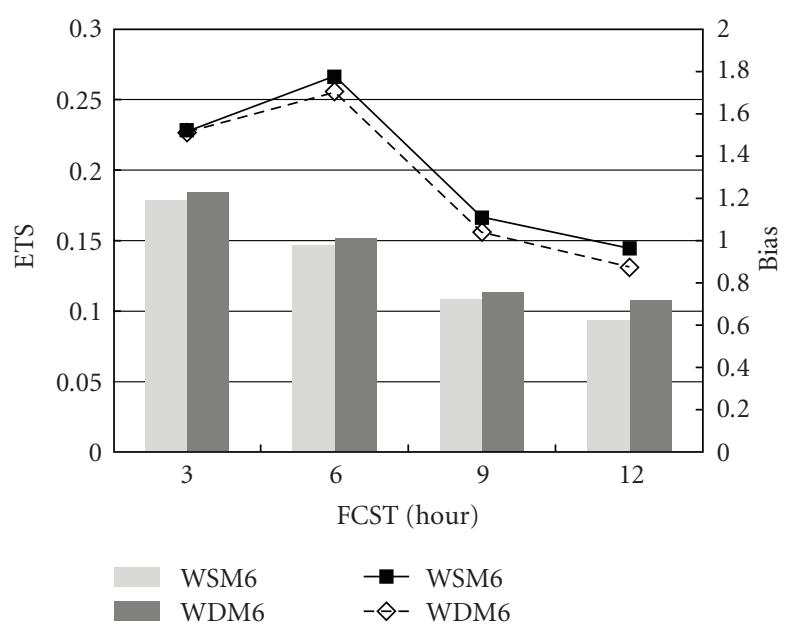

(b)

FIgure 6: The time series of the equitable threat score (ETS; bars) and bias score (Bias; lines) for 3 hours accumulated precipitation over South Korea during the 12 hours forecast period, for (a) light precipitation ( $1 \mathrm{~mm} / 3$ hours) and (b) heavy precipitaion $(10 \mathrm{~mm} / 3$ hours) categories. The total number of samples is 976 , which consists of 8 times a day for June-July-August 2008. The number of observation used is about 600 , which is about $13 \mathrm{~km}$ apart over South Korea. The horizontal grid spacing is $5 \mathrm{~km}$ covering the Korean peninsula, which is nested by the $15 \mathrm{~km}$ grid.

a diabatic initialization that carries the hydrometeors at the initial time.

Further study is needed to clarify the physical reasons for the different features in precipitation, but it is assumed that a more realistic variability in cloud and rain number concentrations in the WDM6 scheme provides a realistic convective environment and feedback to cloud microphysics associated with the rainfall embedded within various weather phenomena, including a summer monsoon over East Asia and a squall line in the US. A robust evaluation of microphysical properties such as hydrometeors and associated cloud dynamics should be followed as a future study. 


\section{Acknowledgments}

This research was supported by the Basic Science Research Program through the National Research Foundation of Korea (NRF) funded by the Ministry of Education, Science and Technology (2010-0000840), by the Korean Foundation for International Cooperation Science \& Technology (KICOS) through a grant provided by the Korean Ministry of Science \& Technology (MOST) in 2009, by the project, "Development of the numerical prediction technique for the improved military weather support," through a grant provided by the Republic of Korea Air Force (ROKAF) in 2010, and by the National Institute of Meteorological Research of the Korea Meteorological Administration under a major project "NIMR-2009-C-1." The comments from the anonymous reviewers were helpful. WSI IHOP Sector Mosaic Reflectivity Imagery $(2-\mathrm{km})$ [NCAR/EOL] provided by NCAR/EOL under sponsorship of the National Science Foundation.

\section{References}

[1] W. C. Skamarock, J. B. Klemp, J. Dudhia, et al., "A description of the advanced research WRF version 3," Technical Note TN475+STR, NCAR, 2008.

[2] L. R. Leung, Y.-H. Kuo, and J. Tribbia, "Research needs and directions of regional climate modeling using WRF and CCSM," Bulletin of the American Meteorological Society, vol. 87, no. 12, pp. 1747-1751, 2006.

[3] J. S. Kain, S. J. Weiss, J. J. Levit, M. E. Baldwin, and D. R. Bright, "Examination of convection-allowing configurations of the WRF model for the prediction of severe convective weather: the SPC/NSSL Spring Program 2004," Weather and Forecasting, vol. 21, no. 2, pp. 167-181, 2006.

[4] M. L. Weisman, C. Davis, W. Wang, K. W. Manning, and J. B. Klemp, "Experiences with 0-36-h explicit convective forecasts with the WRF-ARW model," Weather and Forecasting, vol. 23, no. 3, pp. 407-437, 2008.

[5] S.-Y. Hong and J.-O. J. Lim, "The WRF single-moment 6class microphysics scheme (WSM6)," Journal of the Korean Meteorological Society, vol. 42, no. 2, pp. 129-151, 2006.

[6] S.-Y. Hong, J. Dudhia, and S.-H. Chen, "A revised approach to ice microphysical processes for the bulk parameterization of clouds and precipitation," Monthly Weather Review, vol. 132, no. 1, pp. 103-120, 2004.

[7] C. M. Shafer, A. E. Mercer, C. A. Doswell III, M. B. Richman, and L. M. Leslie, "Evaluation of WRF forecasts of tornadic and nontornadic outbreaks when initialized with synoptic-scale input," Monthly Weather Review, vol. 137, no. 4, pp. 12501271, 2009.

[8] C. S. Schwartz, J. S. Kain, S. J. Weiss, et al., "Next-day convection-allowing WRF model guidance: a second look at 2-km versus 4-km grid spacing," Monthly Weather Review, vol. 137, no. 10, pp. 3351-3372, 2009.

[9] J.-C. Ha, Y.-H. Lee, J.-S. Lee, H.-C. Lee, and H.-S. Lee, "Development of short range analysis and prediction system," in Proceedings of the 9th Weather Research and Forecasting Model Workshop, pp. 1-4, NCAR Mesoscale and Microscale Meteorology Division, Boulder, Colo, USA, 2008, http://www.mmm.ucar.edu/wrf/users/workshops/.

[10] U.-Y. Byun, H.-W. Kim, Y.-K. Son, and Y.-K. Yum, "Evaluation of the KAF-WRF model during a summer season," in
Autumn Meeting, Korean Meteorological Society, pp. 324-325, Kyungpook National University, Daegu, South Korea, 2009, http://www.komes.or.kr/journal_search/ISS_GotoSearch.php.

[11] K. A. James, D. J. Stensrud, and N. Yussouf, "Value of real-time vegetation fraction to forecasts of severe convection in highresolution models," Weather and Forecasting, vol. 24, no. 1, pp. 187-210, 2009.

[12] X. Li and Z. Pu, "Sensitivity of numerical simulation of early rapid intensification of Hurricane Emily (2005) to cloud microphysical and planetary boundary layer parameterizations," Monthly Weather Review, vol. 136, no. 12, pp. 48194838, 2008.

[13] H. Shin and S.-Y. Hong, "Quantitative precipitation forecast experiments of heavy rainfall over Jeju Island on 14-16 September 2007 using the WRF model," Asia-Pacific Journal of Atmospheric Sciences, vol. 45, no. 1, pp. 71-89, 2009.

[14] J. G. Powers, "Numerical prediction of an Antarctic severe wind event with the Weather Research and Forecasting (WRF) model," Monthly Weather Review, vol. 135, no. 9, pp. 31343157, 2007.

[15] X.-Y. Huang, Q. Xiao, D. M. Barker, et al., "Four-dimensional variational data assimilation for WRF: formulation and preliminary results," Monthly Weather Review, vol. 137, no. 1, pp. 299-314, 2009.

[16] J. A. Otkin and T. J. Greenwald, "Comparison of WRF modelsimulated and MODIS-derived cloud data," Monthly Weather Review, vol. 136, no. 6, pp. 1957-1970, 2008.

[17] J. J. Shi, W.-K. Tao, S. Lang, S. S. Chen, S.-Y. Hong, and C. Peters-Lidard, "An improved bulk microphysical scheme for studying precipitation processes: comparisons with other schemes," in AGU Joint Assembly, Acapulco, Mexico, May 2007, American AU11 Geophysical Union, ID A41D-02, http://www.agu.org/.

[18] Y. Lin and B. A. Colle, "The 4-5 December 2001 IMPROVE2 event: observed microphysics and comparisons with the weather research and forecasting model," Monthly Weather Review, vol. 137, no. 4, pp. 1372-1392, 2009.

[19] I.-H. Jo, K.-D. An, E.-H. Lim, and D.-U. Chang, "Improvement of the precipitation forecasting of a lightprecipitation category in the WRF microphysics scheme during a winter season," in Autumn Meeting, Korean Meteorological Society, pp. 248-249, Kongju National University, Daejeon, South Korea, 2008, http://www.komes.or .kr/journal_search/ISS_GotoSearch.php.

[20] J. Dudhia, S.-Y. Hong, and K.-S. Lim, "A new method for representing mixed-phase particle fall speeds in bulk microphysics parameterizations," Journal of the Meteorological Society of Japan, vol. 86A, pp. 33-44, 2008.

[21] K.-S. S. Lim and S.-Y. Hong, "Development of an effective double-moment cloud microphysics scheme with prognostic Cloud Condensation Nuclei (CCN) for weather and climate models," Monthly Weather Review, vol. 138, pp. 1587-1612, 2010.

[22] H. Morrison, G. Thompson, and V. Tatarskii, "Impact of cloud microphysics on the development of trailing stratiform precipitation in a simulated squall line: comparison of oneand two-moment schemes," Monthly Weather Review, vol. 137, no. 3, pp. 991-1007, 2009.

[23] S. Twomey, "The nuclei of natural cloud formation part II: the supersaturation in natural clouds and the variation of cloud droplet concentration," Pure and Applied Geophysics, vol. 43, no. 1, pp. 243-249, 1959.

[24] M. Khairoutdinov and Y. Kogan, "A new cloud physics parameterization in a large-eddy simulation model of marine 
stratocumulus," Monthly Weather Review, vol. 128, no. 1, pp. 229-243, 2000.

[25] J.-M. Cohard and J.-P. Pinty, "A comprehensive two-moment warm microphysical bulk scheme. I: description and tests," Quarterly Journal of the Royal Meteorological Society, vol. 126, no. 566, pp. 1815-1842, 2000.

[26] J. S. Kain and J. Kain, "The Kain-Fritsch convective parameterization: an update," Journal of Applied Meteorology, vol. 43, no. 1, pp. 170-181, 2004.

[27] F. Chen and J. Dudhia, "Coupling and advanced land surfacehydrology model with the Penn State-NCAR MM5 modeling system. Part I: model implementation and sensitivity," Monthly Weather Review, vol. 129, no. 4, pp. 569-585, 2001.

[28] J. Dudhia, "Numerical study of convection observed during the winter monsoon experiment using a mesoscale twodimensional model," Journal of the Atmospheric Sciences, vol. 46, no. 20, pp. 3077-3107, 1989.

[29] E. J. Mlawer, S. J. Taubman, P. D. Brown, M. J. Iacono, and S. A. Clough, "Radiative transfer for inhomogeneous atmospheres: RRTM, a validated correlated-k model for the longwave," Journal of Geophysical Research D, vol. 102, no. 14, pp. 16663 16682, 1997.

[30] S.-Y. Hong, Y. Noh, and J. Dudhia, "A new vertical diffusion package with an explicit treatment of entrainment processes," Monthly Weather Review, vol. 134, no. 9, pp. 2318-2341, 2006.

[31] Z. Janjic, "Nonsigular implementation of the Mellor-Yamada level 2.5 scheme in the NCEP global model," NCEP Office Note, no. 437, 2002.

[32] G. L. Mellor and T. Yamada, "Development of a turbulence closure model for geophysical fluid problems," Reviews of Geophysics \& Space Physics, vol. 20, no. 4, pp. 851-875, 1982.

[33] M.-S. Koo and S.-Y. Hong, "Diurnal variations of simulated precipitation over East Asia in two regional climate models," Journal of Geophysical Research D, vol. 115, no. 5, Article ID D05105, 17 pages, 2010.

[34] G. J. Huffman, R. F. Adler, D. T. Bolvin, et al., "The TRMM multisatellite precipitation analysis (TMPA): quasi-global, multiyear, combined-sensor precipitation estimates at fine scales," Journal of Hydrometeorology, vol. 8, no. 1, pp. 38-55, 2007.

[35] T. D. Crum and R. L. Alberty, "The WSR-88D and the WSR88D operational support facility," Bulletin of the American Meteorological Society, vol. 74, no. 9, pp. 1669-1687, 1993.

[36] W. Heiss, D. McGrew, and D. Sirmans, "NEXRAD: next generation weather radar (WSR-88D)," Microwave Journal, vol. 33, pp. 79-98, 1990.

[37] G. Thompson, P. R. Field, W. D. Hall, and R. M. Rasmussen, "A new bulk microphysical parameterization for WRF and MM6," in Proceedings of the 7th Weather Research and Forecasting Model Workshop, pp. 1-11, NCAR Mesoscale and Microscale Meteorology Division, Boulder, Colo, USA, 2006, http://www.mmm.ucar.edu/wrf/users/workshops/.

[38] M. L. Weisman, W. Wang, and K. Manning, "The use of the RUC DFI initialization for the 2009 WRF-ARW 3 $\mathrm{km}$ explicit convective forecasts," in Proceedings of the 10th Weather Research and Forecasting Model Workshop, pp. 118, NCAR Mesoscale and Microscale Meteorology Division, Boulder, Colo, USA, 2009, http://www.mmm.ucar.edu/ wrf/users/workshops/.

[39] G. Thompson, P. R. Field, R. M. Rasmussen, and W. D. Hall, "Explicit forecasts of winter precipitation using an improved bulk microphysics scheme. Part II: implementation of a new snow parameterization," Monthly Weather Review, vol. 136, no. 12 , pp. 5095-5115, 2008.
[40] J. W. Wilson and R. D. Roberts, "Summary of convective storm initiaiton and evolution during IHOP: observational and modeling perspective," Monthly Weather Review, vol. 134, no. 1, pp. 23-47, 2006.

[41] G. A. Grell, J. Dudhia, and D. R. Stauffer, "A description of the Fifth-Generation Penn State/NCAR mesoscale model (MM5)," Technical Note TN-398+STR, NCAR, 1994.

[42] S. J. Ghan, L. R. Leung, and J. McCaa, "A comparison of three different modeling strategies for evaluating cloud and radiation parameterizations," Monthly Weather Review, vol. 127, no. 9, pp. 1967-1984, 1999.

[43] F. Su, Y. Hong, and D. P. Lettenmaier, "Evaluation of TRMM multisatellite precipitation analysis (TMPA) and its utility in hydrologic prediction in the La Plata Basin," Journal of Hydrometeorology, vol. 9, no. 4, pp. 622-640, 2008. 

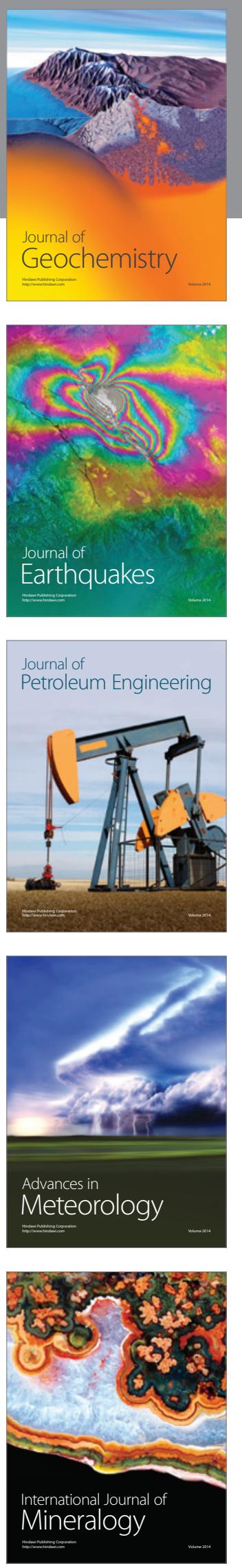
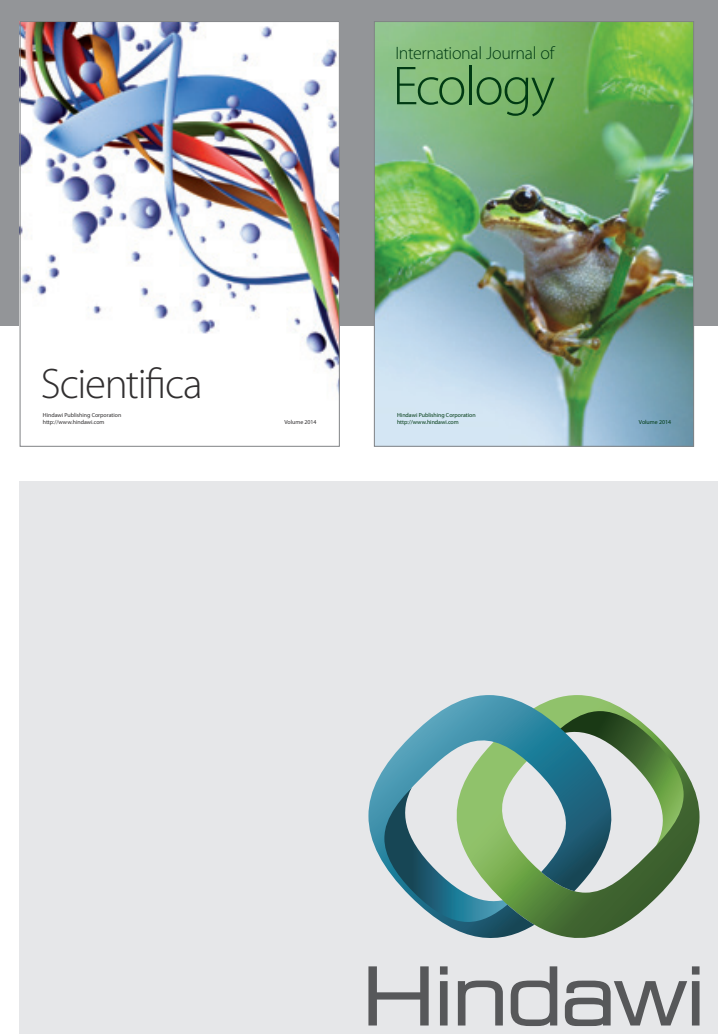

Submit your manuscripts at http://www.hindawi.com
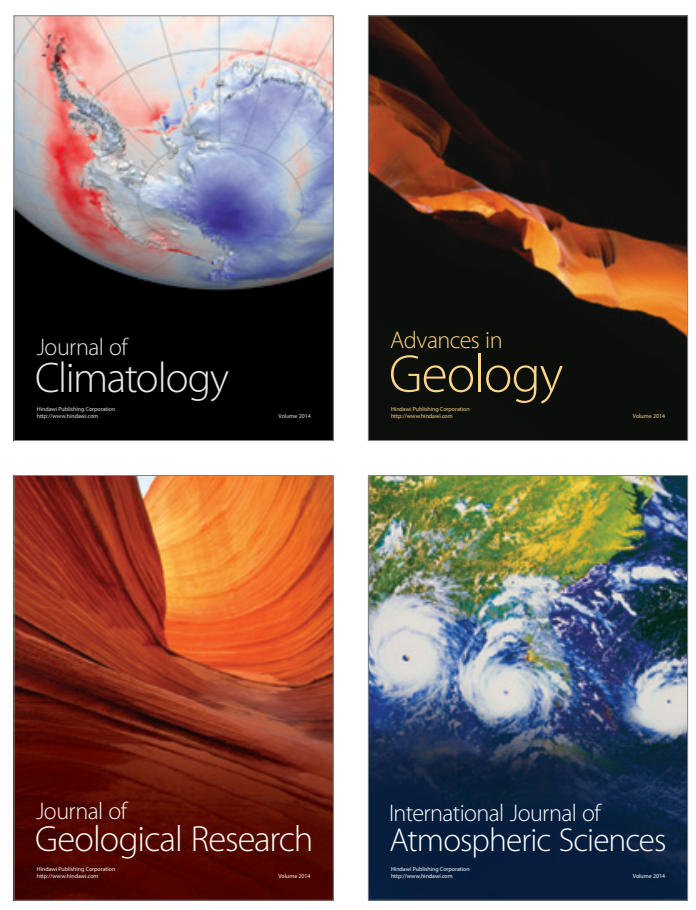
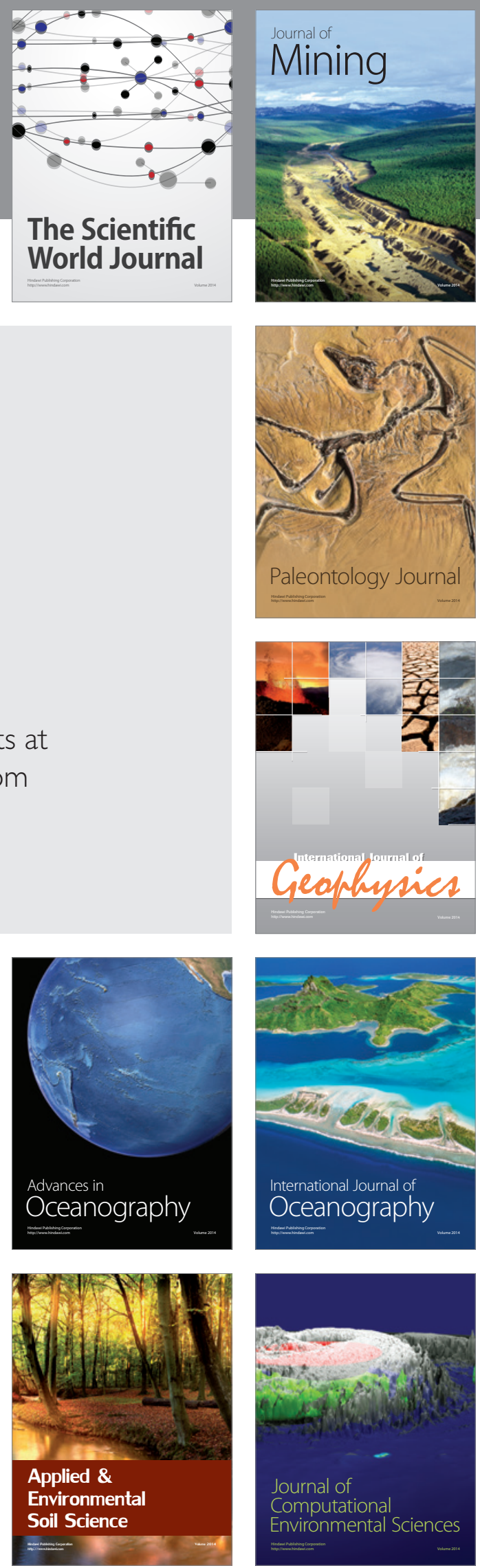